\title{
PLASMA PROTEIN $N$-GLYCAN SIGNATURES OF TYPE 2 DIABETES
}

Viktoria Dotz $^{\mathrm{a}^{*}}$ (v.dotz@lumc.nl), Roosmarijn F.H. Lemmers ${ }^{\mathrm{b}, \mathrm{c}^{*}}$ (r.lemmers@erasmusmc.nl), Karli R. Reidinga (k.r.reiding@lumc.nl), Agnes L. Hipgrave Ederveen ${ }^{\mathrm{a}}$ (a.1.hipgrave_ederveen@lumc.nl), Aloysius G. Lieverse ${ }^{c}$ (1.lieverse@mmc.nl), Monique T. Mulder $^{\mathrm{b}}$ (m.t.mulder@erasmusmc.nl), Eric J.G. Sijbrands ${ }^{\mathrm{b}}$ (e.sijbrands@erasmusmc.nl), Manfred Wuhrer ${ }^{\mathrm{a}}$ (m.wuhrer@lumc.nl), Mandy van Hoek ${ }^{\mathrm{b}}$ (m.vanhoek@erasmusmc.nl)

${ }^{\text {a }}$ Center for Proteomics and Metabolomics, Leiden University Medical Center, Leiden, the Netherlands

${ }^{\mathrm{b}}$ Department of Internal Medicine, ErasmusMC, University Medical Center, Rotterdam, the Netherlands

${ }^{\mathrm{c}}$ Department of Internal Medicine, Máxima Medical Center, Eindhoven, the Netherlands

* Authors contributed equally

Corresponding author: Mandy van Hoek, Department of Internal Medicine, Erasmus Medical Center, Rotterdam, the Netherlands, + 31 633343603, m.vanhoek@erasmusmc.nl

Abbreviations: BMI, body mass index; HbA1c, glycated hemoglobin; HDL, high-density lipoprotein; HDL-c, HDL-cholesterol; HNF 1A, hepatocyte nuclear factor 1- $\alpha$ (gene); Ig, immunoglobulin; MODY, maturity onset diabetes of the young; OR, odds ratio; SD, standard deviation; ST6Gal1, beta-galactoside alpha-2,6-sialyltransferase-1 


\section{ABSTRACT}

Background: Little is known about enzymatic $N$-glycosylation in type 2 diabetes, a common posttranslational modification of proteins influencing their function and integrating genetic and environmental influences. We sought to gain insights into $N$-glycosylation to uncover yet unexplored pathophysiological mechanisms in type 2 diabetes.

Methods: Using a high-throughput MALDI-TOF mass spectrometry method, we measured $N$-glycans in plasma samples of the DiaGene case-control study (1583 cases and 728 controls). Associations were investigated with logistic regression and adjusted for age, sex, body mass index, high-density lipoprotein-cholesterol, non-high-density lipoprotein-cholesterol, and smoking. Findings were replicated in a nested replication cohort of 232 cases and 108 controls.

Results: Eighteen glycosylation features were significantly associated with type 2 diabetes. Fucosylation and bisection of diantennary glycans were decreased in diabetes (odds ratio $(\mathrm{OR})=$ $0.81, \mathrm{p}=1.26 \mathrm{E}-03$, and $\mathrm{OR}=0.87, \mathrm{p}=2.84 \mathrm{E}-02$, respectively), whereas total and, specifically, alpha2,6-linked sialylation were increased $(\mathrm{OR}=1.38, \mathrm{p}=9.92 \mathrm{E}-07$, and $\mathrm{OR}=1.40, \mathrm{p}=5.48 \mathrm{E}-$ 07). Alpha2,3-linked sialylation of triantennary glycans was decreased $(\mathrm{OR}=0.60, \mathrm{p}=6.38 \mathrm{E}-11)$.

Conclusions: While some glycosylation changes were reflective of inflammation, such as increased alpha2,6-linked sialylation, our finding of decreased alpha2,3-linked sialylation in type 2 diabetes patients is contradictory to reports on acute and chronic inflammation. Thus, it might have previously unreported immunological implications in type 2 diabetes.

General significance: This study provides new insights into $\mathrm{N}$-glycosylation patterns in type 2 diabetes, which can fuel studies on causal mechanisms and consequences of this complex disease.

Keywords: diabetes complications, diabetes mellitus, inflammation; MALDI-TOF-MS; $N$ glycosylation; sialic acid 


\section{INTRODUCTION}

Diabetes mellitus type 2 is a disease with enormous morbidity and excess mortality [1]. Intensive therapy can reduce the burden of complications of the disease, but only to about $50 \%$ [2]. It is well-recognized as a multifactorial disease in which genetic susceptibility, numerous metabolic pathways, lifestyle and environmental factors interact at multiple levels [3]. These factors are known to also influence protein $N$-glycosylation [4-6]. Glycomics is a relatively new 'omics' approach that analyses complex sugar structures (glycans), which are among the four principal cell components besides DNA, proteins, and lipids [4]. Pathophysiological processes in type 2 diabetes are intricate and incompletely understood. 'Omics' approaches may increase our understanding of the pathophysiology and eventually advance the development of personalized diabetes medicine, early detection, and more effective treatment approaches [7].

Little is known about the enzymatic process called $\mathrm{N}$-glycosylation in type 2 diabetes. $\mathrm{N}$ Glycosylation is a common posttranslational modification of proteins involving the action of hundreds of different proteins such as glycosyltransferases, glycosidases, and transporters [4, 8]. Carbohydrate metabolic pathways are directly related to the biosynthesis of monosaccharides that are the substrates for glycosylation [6]. $\mathrm{N}$-Glycans are highly diverse and have multiple functions, including important roles in protein folding, stability, and receptor-ligand interaction $[4,8] . \mathrm{N}$ Glycosylation is not to be confused with non-enzymatic glycation, such as in glycated hemoglobin (HbA1c) and in advanced glycation end products, which has been extensively investigated and is well-known for its detrimental effects on plasma proteins and DNA [9].

Most of the major plasma proteins are glycosylated and $N$-glycans have already been proposed as biomarkers and therapeutic targets for various inflammatory diseases and cancer [4]. In healthy individuals, plasma protein glycosylation is constant over time, but can dramatically change because of a pathological condition, especially upon inflammation $[10,11]$. Furthermore, $N$-glycosylation changes have been associated with obesity, smoking, and aging [12-15], which are recognized risk factors for type 2 diabetes. However, a limited number of reports exist on plasma $N$-glycosylation in diabetes. Fucosylation of plasma $N$-glycans is partly regulated by hepatocyte nuclear factor 1- $\alpha(H N F 1 A)$ [16], of which rare variants cause type 3 maturity-onset diabetes of the young (MODY) [17] and of which a common genetic variant has been linked to type 2 diabetes [18]. Recently, we found decreased galactosylation and sialylation and increased bisection of fucosylated structures on immunoglobulin $(\mathrm{Ig}) \mathrm{G}$ in type 2 diabetes, which corresponds with an increased inflammatory potential of IgG [19]. Reduced IgG sialylation in mice was shown to be implicated in obesity-induced insulin resistance [20]. In total plasma $N$-glycome, Testa et al. found that monogalactosylated, core-fucosylated diantennary $\mathrm{N}$-glycans were reduced in individuals with type 2 diabetes compared to controls [21]. In this promising pioneering work, a limited number of glycan structures were detected after the removal of sialic acids. Sialylation, however, has a crucial role in the functionality of $N$-glycans [22], and total plasma levels of sialic acid have been associated with incident type 2 diabetes [23, 24]. Recently, associations of increased complexity and sialylation of plasma $N$-glycan structures with a higher risk of type 2 diabetes were reported [25]. Therefore, comprehensive research of the total plasma $N$-glycome, 
including detailed sialylation analyses, is indicated to understand the contribution of these multifaceted structural glycan features to this complex disease. Our MALDI-TOF MS-based highthroughput approach is well suited for this purpose, as it identifies 70 glycan compositions and reveals information on not only fucosylation, bisection and sialylation [26], but also on sialic-acid linkage variants that have not been previously investigated.

In the present study, we sought to reveal differences in the detailed structural features of the plasma $\mathrm{N}$-glycome between type 2 diabetes patients and healthy controls in a large case-control study, and performed a nested replication in a subsample of the population to gain a first insight into the possible involvement of plasma protein $\mathrm{N}$-glycans in the pathophysiology of type 2 diabetes.

\section{MATERIAL AND METHODS}

\subsection{Subjects}

Plasma samples from the DiaGene study were used for the $\mathrm{N}$-glycan measurements. DiaGene is a case-control study on type 2 diabetes (1886 cases and 854 controls) collected from the Eindhoven area in the Netherlands and is described in detail elsewhere [27], with basic characteristics summarized in Table 1. All samples were collected and stored according to the same protocol as described previously. The control samples were collected, stored and processed on the same location as the primary care patient samples.

All participants have given written informed consent. The study was approved by the Medical Ethical Committee of the Erasmus MC and is in compliance with the Declaration of Helsinki principles.

\subsection{Total plasma $N$-glycome analysis and MS data processing}

$N$-Glycans were analyzed after sialic-acid derivatization by a previously established MALDI-TOF MS method [26, 28], with minor modifications. Briefly, $5 \mu$ L plasma sample was denatured by the addition of $10 \mu \mathrm{L}$ of $2 \%$ sodium dodecyl sulfate and incubation for $10 \mathrm{~min}$ at 60 ${ }^{\circ} \mathrm{C}$. For glycan release, $10 \mu \mathrm{L}$ of $2.5 \times$ phosphate-buffered saline containing $2 \%$ nonidet P-40 and $0.5 \mathrm{mU}$ peptide- $\mathrm{N}$-glycosidase F (Roche Diagnostics, Mannheim, Germany) were added followed by incubation for $16 \mathrm{~h}$ at $37^{\circ} \mathrm{C}$. Thereafter, during the derivatization procedure, $\alpha 2,6$-linked sialic acids were ethyl-esterified and $\alpha 2,3$-linked sialic acids were lactonized, facilitating mass-based discrimination of sialic-acid linkage variants. Released glycans were purified using a 96-well filter plate with a GHP membrane (AcroPrep Advance 96 Filter plate, Pall Corporation, Ann Arbor, MI) on a Hamilton liquid-handling system. The derivatized sialylated glycans were detected simultaneously with nonsialylated $N$-glycans in positive-ion reflectron mode. In short, $10 \mu \mathrm{L}$ of sample was premixed with $10 \mu \mathrm{L}$ of $5 \mathrm{mg} / \mathrm{mL}$ super-DHB (Sigma-Aldrich, Steinheim, Germany) in $99 \%$ acetonitrile with $1 \mathrm{mM} \mathrm{NaOH}$ in a 384-well plate, $2 \mu \mathrm{L}$ of which was spotted on plate. Mass spectra were acquired by an ultrafleXtreme MALDI-TOF mass spectrometer equipped with a Smartbeam-II laser operated by flexControl 3.4 (Build 135) (Bruker Daltonics, Bremen, 
Germany). A total of 20,000 shots at $1,000 \mathrm{~Hz}$ were accumulated per spectrum with a mass range of $m / z$ 1,000-5,000. The MALDI-TOF-MS was calibrated using the Bruker Peptide Calibration Standard II. An acceleration voltage of $25 \mathrm{kV}$ was applied following a $140 \mathrm{~ns}$ extraction delay. Using flexAnalysis 3.4 (Build 76) Batch Process, raw data were baseline-subtracted (TopHat) and smoothed (SavitzkyGolay), and .xy files were generated for further processing.

Table 1. Characteristics of the study populations.

\begin{tabular}{|c|c|c|c|c|}
\hline & \multicolumn{2}{|l|}{ Discovery cohort } & \multicolumn{2}{|l|}{ Replication cohort } \\
\hline & Cases & Controls & Cases & Controls \\
\hline Total number & 1583 & 728 & 232 & 108 \\
\hline Age (years) & $65.2 \pm 10.9$ & $65.8 \pm 7.0$ & $65.1 \pm 7.8$ & $65.8 \pm 5.0$ \\
\hline Sex (female) $(n, \%)$ & $748(47.3)$ & $456(62.6)^{\mathrm{c}}$ & $90(38.8)$ & $42(38.9)$ \\
\hline $\mathrm{BMI}\left(\mathrm{kg} / \mathrm{m}^{2}\right)$ & $29.4(26.6-33.0)$ & $25.4(23.3-27.8)^{\mathrm{c}}$ & $30(27.4-34)$ & $25.8(23.7-27.9)^{\mathrm{c}}$ \\
\hline HDL-c (mmol/l) & $1.10(0.94-1.30)$ & $1.42(1.22-1.67)^{\mathrm{c}}$ & $1.18(1.00-1.40)$ & $1.39(1.19-1.64)^{\mathrm{c}}$ \\
\hline Non-HDL-c (mmol/l) & $3.00(2.50-3.68)$ & $4.03(3.43-4.76)^{\mathrm{c}}$ & $2.85(2.4-3.46)$ & $4.19(3.54-4.66)^{\mathrm{c}}$ \\
\hline Creatinine $(\mu \mathrm{mol} / \mathrm{l})$ & $77(67-92)$ & $71(63-80)^{\mathrm{c}}$ & $77(66-91)$ & $77(67-86)$ \\
\hline Ever smoked (n, \%) & $1079(74.3)$ & $480(68.4)^{\mathrm{b}}$ & $158(75.2)$ & $64(61.0)^{\mathrm{a}}$ \\
\hline Currently smoking (n, \%) & $260(18.1)$ & $80(11.4)^{\mathrm{c}}$ & $34(16.3)$ & $9(8.6)$ \\
\hline Systolic BP (mmHg) & $142 \pm 19$ & $139 \pm 20^{\mathrm{b}}$ & $142 \pm 19$ & $139 \pm 18$ \\
\hline Cardiovascular disease $(\mathrm{n}, \%)$ & $539(37.1)$ & $66(9.4)^{\mathrm{c}}$ & $89(41.2)$ & $0^{\mathrm{c}}$ \\
\hline HbA1c (mmol/mol) & $50.8(45.4-59.6)$ & $37.7(35.5-38.8)^{\mathrm{c}}$ & $51.9(45.4-60.7)$ & $36.6(35.5-38.8)^{\mathrm{c}}$ \\
\hline Duration of diabetes (years) & $8(3-14)$ & $\mathrm{NA}$ & $10(5-16)$ & NA \\
\hline Insulin use $(\mathrm{n}, \%)$ & $452(30.3)$ & NA & $89(40.1)$ & NA \\
\hline Diabetic retinopathy $(\mathrm{n}, \%)$ & $223(15.0)$ & NA & $68(29.4)$ & NA \\
\hline Diabetic nephropathy $(\mathrm{n}, \%)$ & $311(22.2)$ & NA & $56(25.7)$ & NA \\
\hline
\end{tabular}

Continuous data are represented as median and interquartile range or as mean \pm SD in case of age and systolic blood pressure (BP). Clinical variables were compared between cases and controls with the Student's t-test or the Wilcoxon rank-sum test for normal and non-normal distributions, respectively, and with the $\chi 2$-test for binary data. All $p$-values are shown for cases $v s$. controls within the same cohort: ${ }^{\mathrm{a}} p<0.05 ;{ }^{\mathrm{b}} p<0.01 ;{ }^{\mathrm{c}} p<0.001$. BMI, body mass index; BP, blood pressure; HbA1c, glycated hemoglobin; HDL-c, high-density lipoprotein cholesterol; NA = not applicable.

For the analyte composition list, three sum spectra were generated from selected mass spectra from cases with and cases without diabetic complications, and healthy controls, eight mass spectra per group. In addition to the manual inspection of the peaks in the sum spectra, potential modifications for the 20 most abundant glycan compositions, including fragments, potassium adducts, and adducts from the derivatization reaction were considered, resulting in a list of 159 potential analytes with a distinct $m / z$ value (Supplementary Table S1). Our in-house built software MassyTools version 0.1.8.1.2 [29] was used for area integration and internal calibration, with a 
list of high-intensity glycan signals distributed across the detected $m / z$ range applied as calibrants: H3N4F1, H4N4F1, H5N4F1, H5N4E1F1, H6N5L1E2, H6N5L1E2F1 (Supplementary Table S1). The relative areas of the detected glycans were extracted by summing the isotopes within $80 \%$ of the isotopic envelope for each species. Furthermore, different quality parameters (see below) were calculated using MassyTools. Resulting mass errors and relative standard deviations (SD) of the calculated relative intensities of the glycan compositions are presented in Supplementary Table $\mathrm{S} 1$. For example, the relative SD of the main peak at $\mathrm{m} / \mathrm{z} 2301$ was $6.42 \%$.

Mass spectra were excluded from further analysis if their total intensity was lower than 50,000 and their "Fraction of analyte area - background area above signal-to-noise ratio" was lower than 0.89 (corresponding to the mean minus 4-times the SD to ensure a sufficient intensity for the overall profile including minor peaks; see [29] for further details on the quality parameters). The reasoning for setting the cut-offs was confirmed by a manual inspection of several borderline spectra. After the removal of low-quality spectra, analyte compositions were removed from further analysis based on cut-offs for their signal-to-noise ratio, mass accuracy, isotopic pattern quality, and presence in a minimum percentage of the spectra within cases, healthy controls, or VisuConF plasma standard samples (Stago BNL, Netherlands). The cut-off values were as follows: signalto-noise $>6$, ppm error $<20$, deviation from the theoretical isotopic pattern $<20 \%$, and present in at least $10 \%$ of spectra per group, i.e. cases, controls, or plasma standards. Only non-modified glycan compositions were further processed. The sum of the signal intensities of these remaining 70 compositions was normalized to 1 , with each individual composition expressing a fraction thereof (total area normalization; see Figure 1 and Supplementary Table S1). From the 70 direct traits, 91 derived traits were calculated on the basis of their structural features (Supplementary Table S2) [25, 26, 30]. In case of ambiguity due to isomerism, for example in H5N5E1F1, bisection of diantennary glycans was assumed rather than an agalactosylated third antenna.

\subsection{Experimental design and statistical analysis}

In total, 2718 samples from the DiaGene cohort, 31 blanks and 155 VisuCon-F standard plasma samples were randomized over 31 96-well plates and prepared and analyzed as described above. After the removal of low-quality spectra during quality control and samples with insufficient clinical information, the discovery cohort data consisted of 1583 cases and 728 controls. For the nested replication cohort, 232 cases were randomly selected using IBM SPSS Statistics (version 21.0) and 108 controls were selected matching on average age and sex frequencies as a group. A power calculation was performed using $\mathrm{G}^{*}$ Power 3.1 [31]. At alpha= 0.05 , we had $80 \%$ power to find odds ratios (ORs) $<0.88$ or $>1.13$ in the discovery cohort.

Statistical analyses were performed in RStudio (version 1.0.136). The distribution of the clinical variables was considered normal when Skewness and Kurtosis were within the range of 1 to +1 . Clinical variables were compared between cases and controls with the Student's t-test or the Wilcoxon rank-sum test for normal and non-normal distributions, respectively. Binary data were compared with the $\chi 2$-test. 
Direct and derived glycan traits were adjusted for batch effects by preparation day, MALDI plate, row and column effect using ComBat package in R. For the analyses of associations of $N$ glycans with clinical variables and diabetes, $N$-glycan relative intensities were centered by subtracting the mean and scaled by dividing by the SD. Linear regression was used for associations of $\mathrm{N}$-glycans with continuous clinical variables, and logistic regression for associations with sex and smoking. Age, sex, and their interaction were used as covariates in a second model for the analysis of associations between $\mathrm{N}$-glycans and clinical variables. For the sake of power, we chose to analyze the associations between $\mathrm{N}$-glycans and clinical parameters in the entire cohort instead of stratifying for case/control status.

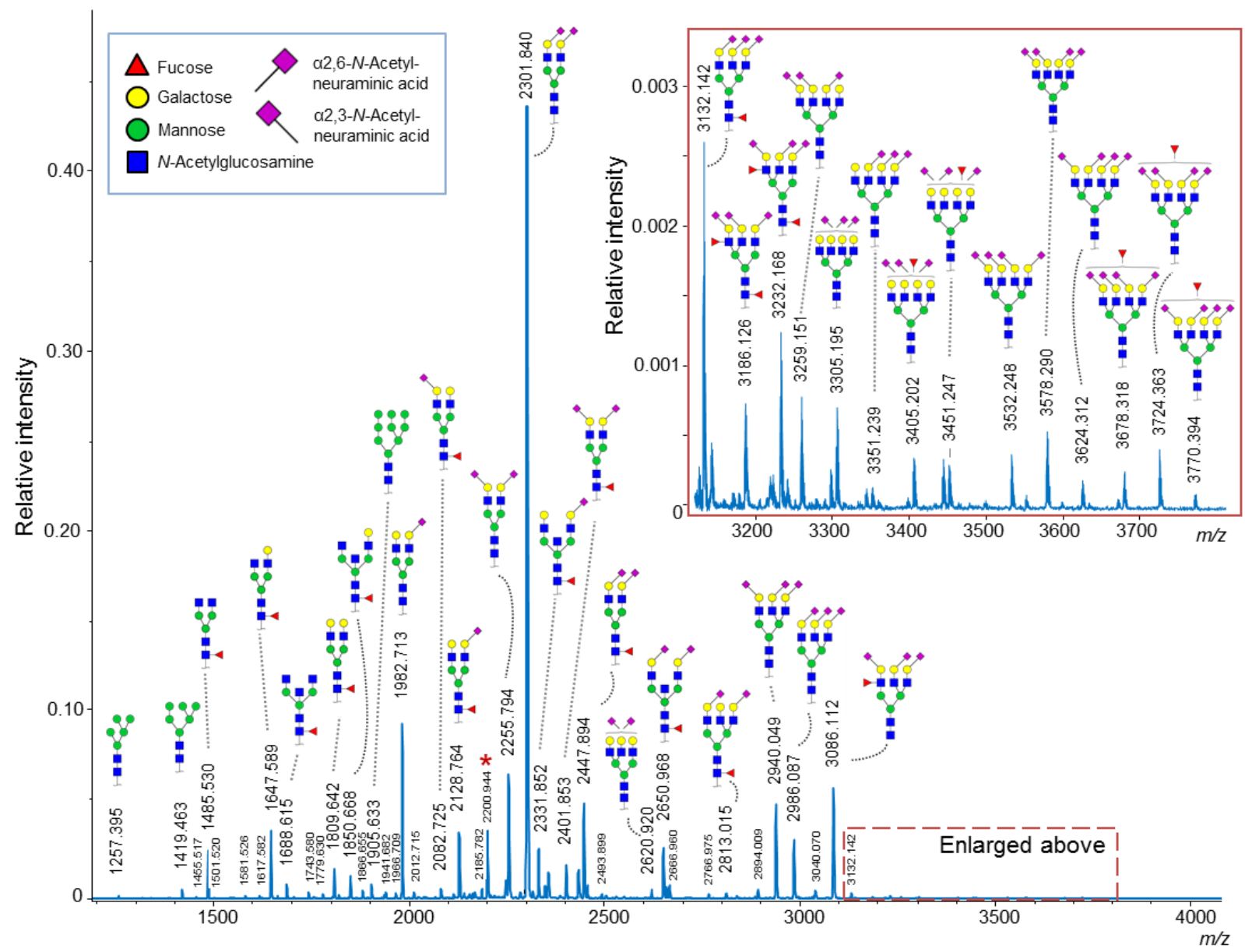

Figure 1: A typical MALDI-TOF mass spectrum of plasma protein $\boldsymbol{N}$-glycans from the DiaGene cohort. After enzymatic release of glycans, sialic acids were stabilized in linkage-specific manner and analyzed by positive-ion reflectron mode MALDI-TOF-MS. Observed $\mathrm{m} / z$ values for $[\mathrm{M}+\mathrm{Na}]^{+}$species are depicted, with structures proposed for the most abundant species. The red asterisk marks a fragment of the species detected at $m / z 2301.840$. For the complete list of, in total, 70 quantified glycan species, see Supplementary Table S1. The inset shows the enlarged mass window of $m / z 3130-3800$. 
Associations of $N$-glycans with type 2 diabetes were assessed with logistic regression. The following covariates were included in three models: 1) age, sex, and their interaction; 2) model 1 + body mass index (BMI); and 3) model 2 + high-density lipoprotein-cholesterol (HDL-c), nonHDL-c, smoking. Outcomes of model 1 reflect the broad differences between cases and controls, while model 2 and 3 more specifically reflect the differences that are not mediated through risk factors for type 2 diabetes. The age-sex interaction was included as a covariate, since it was previously reported to affect various glycan traits [15]. Non-HDL-c was calculated as total cholesterol minus HDL-c. Smoking was divided in current smokers $v s$. former and non-smokers ('Current smoking') and in current and former smokers ('Ever having smoked') vs. non-smokers. Whenever values were missing per clinical variable in models 2 and 3, cases were excluded in the respective statistical analysis using the complete.cases() function in $\mathrm{R}$; the exact numbers of cases and controls per analysis are stated in Table 2. Glycomic data was complete in all cases used for statistical analysis. Calculated ORs refer to an increase of one SD in the tested glycan traits. The Benjamini-Hochberg procedure [32] was applied to control for multiple testing, using a cutoff of $q=0.05$ (5\% false discovery rate).

\section{RESULTS}

\subsection{Data reliability}

The complete list of the 70 quantified glycan compositions as well as additional signals from possible modifications and signals that did not pass our quality criteria is given in Supplementary Table S1. For the quantified species, relative intensities with their relative SD as extracted from technical replicates of 149 plasma standard samples that were randomized and measured together with the cohort samples demonstrate overall method repeatability on the directtrait level. In addition, Supplementary Table S2 contains relative SD values based on our 91 derived glycan traits which were calculated from the 70 direct traits. As described before, derived glycan traits appear to have a higher technical robustness in glycomics studies compared to directly detected compositions [28]. Moreover, derived traits represent the different structural features corresponding to biosynthetic pathways in protein glycosylation as known from literature [25, 26, 30].

\subsection{Subject characteristics}

Detailed characteristics and numbers of the individuals included and excluded from the study are described elsewhere [27]. Details of the cohorts analyzed here for their glycomic signatures are given in Table 1 and glycomics data are shown in Figure 1 and Table S3. In both cohorts, cases had a higher BMI than controls, and a lower HDL-c and non-HDL-c. Moreover, a higher proportion of cases were smokers and had cardiovascular disease (Table 1). Additionally, in the discovery cohort, controls were more often female (62.6\% vs. $47.3 \%)$ and had lower serum creatinine than cases. 


\subsection{Association of glycans with age, sex, and risk factors for type 2 diabetes}

The largest effects associated with increasing age were found for decreased galactosylation and increased bisection of diantennary glycans (Supplementary Figure S2A and Table S4). With increasing age, both $\alpha 2,3$-linked and $\alpha 2,6$-linked sialylation increased for fucosylated glycans, but decreased for non-fucosylated glycans. Different glycosylation features showed strong associations with sex, and moreover, an interaction between age and sex was observed (Supplementary Table S4 and Figure S1).

After adjustment for the covariates age, sex, and their interaction, multiple associations remained significant between glycans and BMI, HDL-c, non-HDL-c, and smoking (excerpt in Figure 2 and full version in Supplementary Figure S2B). For BMI, the strongest associations were with sialylation and sialic-acid linkage. With increasing BMI, overall sialylation increased in diantennary glycans (A2S) and decreased in tetraantennary glycans (A4S). Moreover, higher BMI was associated with lower $\alpha 2,3$-linked (A3L) and higher $\alpha 2,6$-linked sialylation (A2E). In addition, antennary fucosylation and bisection of several nonsialylated traits were positively associated with BMI, whereas bisection of mainly sialylated species and galactosylation of nonsialylated species were inversely associated. Smoking showed an association pattern similar to BMI, but additionally showed strong associations with fucosylation. For a few traits, sialic-acid linkage was associated with BMI and smoking in opposite directions, e.g. in A4F0E and A2(G)L. (Treated) HDL-c and non-HDL-c levels were similarly associated with $N$-glycans, but in the opposite direction from BMI and smoking, particularly regarding sialic-acid linkages. HDL-c and non-HDL-c were associated with low-complexity glycan traits (MM, MHy) in opposite directions (Supplementary Figure S2B).

\subsection{Associations of glycans with type 2 diabetes}

Multiple glycan traits were associated with type 2 diabetes in both the discovery and the replication cohort in all three models (Supplementary Table S5). Adding BMI as a covariate in model 2 affected $p$-values and effect sizes compared to model 1, but did not alter the direction of the associations and only few lost statistical significance. The replicated associations that remained significant after adjustment for additional risk factors in model 3 are shown in Table 2. The strongest associations were found for sialylated traits, particularly for di- and triantennary glycans (Figure 3). Sialylation of diantennary traits was higher in individuals with type 2 diabetes than in controls. Regarding sialic-acid linkage, diantennary $\alpha 2,6$-linked sialylation was increased and triantennary a2,3-linked sialylation was decreased in diabetes (A2(F)GE and A3L). In addition to sialylation changes, decreased bisection of mainly fucosylated sialylated diantennary species, and fucosylation of diantennary traits were associated with type 2 diabetes (A2FSB and A2F). Moreover, the total abundance of fucosylated nonsialylated diantennary species (TA2FS0), most likely derived from IgG [33], was decreased (Figure 3; Table 2).

Several derived traits that were associated with type 2 diabetes in the discovery cohort throughout the three models, also showed associations in the same direction in the smaller replication cohort, but lost significance after adjustment for risk factors for type 2 diabetes in model 
3 (Supplementary Table S5). For instance, the abundance of diantennary $N$-glycans (CA2) was lower in type 2 diabetes while that of triantennary $N$-glycans (CA3) was higher. Galactosylation was decreased and bisection increased in traits related to IgG (A2FS0G and A2FS0B). In contrast, galactosylation of sialylated diantennary glycans was increased (A2SG). Alpha2,3-sialylation of tetraantennary species (A4L) was decreased in type 2 diabetes, while $\alpha 2,3$-sialylation of fucosylated diantennary glycans $(\mathrm{A} 2 \mathrm{~F}(\mathrm{G}) \mathrm{L})$ was increased, although only in the models adjusted for BMI (models 2 and 3).

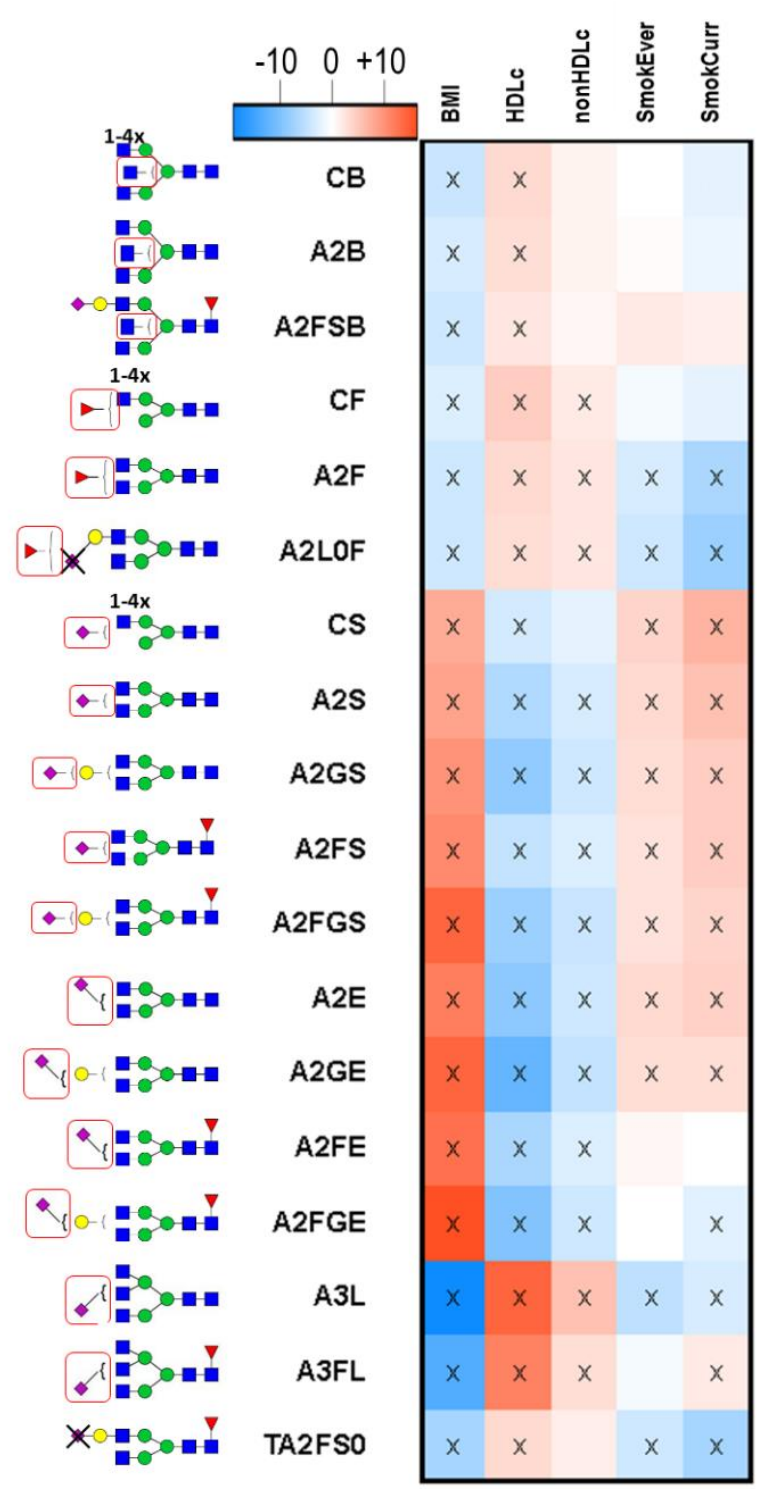

Figure 2: Associations of selected derived glycans with age, sex, BMI, HDL-cholesterol (HDLc), non-HDLc, and smoking for combined data from discovery and replication subsamples. Associations were adjusted for age, sex, and their interaction. Colors represent the t-statistics $(\beta /$ standard error); the $\times$ indicates $p$-values $\leq 0.033$ (significance after FDR-adjustment). See Supplementary Table S2 for glycan derived trait description. Glycan trait abbreviations: B, bisection; $\mathrm{C}$, within complex; A2, diantennary; F, fucosylation; L, $\alpha 2,3$-linked sialylation; $\mathrm{S}$, sialylation; $\mathrm{G}$, galactose; E, a2,6-linked sialylation; A3, triantennary; T, within total. Negative associations with type 2 diabetes are shown in blue, positive associations in red. Ever smoked, SmokEver; currently smoking, SmokCurr.

When assessing the contributions of individual glycan compositions, it becomes apparent that mainly the mono-, di-, and tri- $\alpha 2,6-$ sialylated triantennary glycans H6N5E(1-3) drove the increase of $\mathrm{A} 3 \mathrm{E}$ in diabetes (Supplementary Table S6). Various IgG-related compositions, such as H4N4F1, H5N4F1, and H5N5F1 showed a decrease, as well as various $\alpha 2,3$-sialylated species, such as H7N6(F1)E1L3 and H5N4(F1)E1L1.

\section{DISCUSSION}

Here, we describe associations of multiple plasma protein $N$-glycosylation features with type 2 diabetes. We found that sialylation of diantennary glycans was higher in type 2 diabetes than in healthy controls, while fucosylation and bisection were lower. Intriguingly, diabetes was 
strongly associated with the type of sialic-acid linkage, with lower $\alpha 2,3$-linked sialylation of triantennary glycans and higher $\alpha 2,6$-linked sialylation of diantennary structures.

Table 2. Associations between $N$-glycans and type 2 diabetes.

\begin{tabular}{|c|c|c|c|c|c|c|c|c|c|c|c|c|c|}
\hline \multirow{2}{*}{\multicolumn{2}{|c|}{ Sample number (cases/controls) }} & \multicolumn{4}{|c|}{ Model 1: Age, sex, interaction } & \multicolumn{4}{|c|}{$\begin{array}{l}\text { Model 2: Age, sex, interaction, } \\
\text { BMI }\end{array}$} & \multicolumn{4}{|c|}{$\begin{array}{l}\text { Model 3: Age, sex, interaction, } \\
\text { BMI, HDL-c, nonHDL-c, smoking }\end{array}$} \\
\hline & & \multicolumn{2}{|c|}{$\begin{array}{l}\text { Discovery } \\
1583 / 728\end{array}$} & \multicolumn{2}{|c|}{$\begin{array}{l}\text { Replication } \\
232 / 108\end{array}$} & \multicolumn{2}{|c|}{$\begin{array}{l}\text { Discovery } \\
1457 / 711\end{array}$} & \multicolumn{2}{|c|}{$\begin{array}{l}\text { Replication } \\
232 / 106\end{array}$} & \multicolumn{2}{|c|}{$\begin{array}{l}\text { Discovery } \\
1308 / 650\end{array}$} & \multicolumn{2}{|c|}{$\begin{array}{l}\text { Replication } \\
206 / 100\end{array}$} \\
\hline Trait & $\begin{array}{l}\text { Description } \\
\text { Bisection (B) }\end{array}$ & OR & $\mathbf{p}$ & OR & $\mathbf{p}$ & OR & $\mathbf{p}$ & OR & $\mathbf{P}$ & OR & $\mathbf{p}$ & OR & $\mathbf{p}$ \\
\hline $\mathrm{CB}$ & in complex & 0.82 & 2.17E-05 & 0.62 & $1.10 \mathrm{E}-04$ & 0.86 & 3.37E-03 & 0.61 & 4.14E-04 & 0.86 & $1.45 \mathrm{E}-02$ & 0.53 & $1.42 \mathrm{E}-03$ \\
\hline $\mathrm{A} 2 \mathrm{~B}$ & in diantennary (A2) & 0.85 & 3.02E-04 & 0.64 & $2.69 \mathrm{E}-04$ & 0.87 & $9.80 \mathrm{E}-03$ & 0.61 & 4.73E-04 & 0.87 & $2.84 \mathrm{E}-02$ & 0.54 & $1.53 \mathrm{E}-03$ \\
\hline A2FSB & $\begin{array}{l}\text { in fucosylated sialylated A2 } \\
\text { Fucosylation (F) }\end{array}$ & 0.83 & $9.19 \mathrm{E}-05$ & 0.68 & $1.71 \mathrm{E}-03$ & 0.87 & $1.12 \mathrm{E}-02$ & 0.67 & $5.53 \mathrm{E}-03$ & 0.83 & $5.94 \mathrm{E}-03$ & 0.61 & $1.05 \mathrm{E}-02$ \\
\hline $\mathrm{CF}$ & in complex & 0.77 & $2.45 \mathrm{E}-08$ & 0.62 & $1.21 \mathrm{E}-04$ & 0.78 & $6.10 \mathrm{E}-06$ & 0.60 & $3.61 \mathrm{E}-04$ & 0.80 & $8.46 \mathrm{E}-04$ & 0.61 & $9.05 \mathrm{E}-03$ \\
\hline $\mathrm{A} 2 \mathrm{~F}$ & in diantennary (A2) & 0.77 & 1.17E-08 & 0.61 & $6.53 \mathrm{E}-05$ & 0.79 & $8.24 \mathrm{E}-06$ & 0.59 & 2.33E-04 & 0.81 & $1.26 \mathrm{E}-03$ & 0.61 & $1.14 \mathrm{E}-02$ \\
\hline A2L0F & $\begin{array}{l}\text { in A2 w/o } \alpha 2,3 \text {-sialylation } \\
\text { Sialylation (S) }\end{array}$ & 0.77 & $1.49 \mathrm{E}-08$ & 0.61 & $6.77 \mathrm{E}-05$ & 0.79 & $4.75 \mathrm{E}-06$ & 0.59 & 2.74E-04 & 0.80 & $5.54 \mathrm{E}-04$ & 0.61 & $1.17 \mathrm{E}-02$ \\
\hline $\mathrm{CS}$ & in complex & 1.47 & $2.83 \mathrm{E}-16$ & 1.72 & $1.20 \mathrm{E}-05$ & 1.38 & $8.78 \mathrm{E}-10$ & 1.54 & $2.10 \mathrm{E}-03$ & 1.46 & $7.65 \mathrm{E}-09$ & 1.65 & $8.26 \mathrm{E}-03$ \\
\hline A2S & in diantennary (A2) & 1.50 & $3.31 \mathrm{E}-18$ & 1.95 & $2.68 \mathrm{E}-07$ & 1.38 & $7.83 \mathrm{E}-10$ & 1.80 & $8.54 \mathrm{E}-05$ & 1.38 & $9.92 \mathrm{E}-07$ & 1.87 & $1.78 \mathrm{E}-03$ \\
\hline A2GS & per galactose in A2 & 1.57 & $2.48 \mathrm{E}-21$ & 2.18 & $6.83 \mathrm{E}-09$ & 1.40 & $2.66 \mathrm{E}-10$ & 1.98 & $1.15 \mathrm{E}-05$ & 1.34 & $7.99 \mathrm{E}-06$ & 1.90 & $1.30 \mathrm{E}-03$ \\
\hline A2FS & in fucosylated A2 & 1.61 & $9.72 \mathrm{E}-23$ & 1.89 & $1.32 \mathrm{E}-06$ & 1.46 & $9.88 \mathrm{E}-12$ & 1.59 & $1.80 \mathrm{E}-03$ & 1.55 & $4.09 \mathrm{E}-10$ & 1.75 & $4.19 \mathrm{E}-03$ \\
\hline A2FGS & $\begin{array}{l}\text { per galactose in fucosylated A2 } \\
\boldsymbol{\alpha 2 , 6 - s i a l y l a t i o n ~ ( E ) ~}\end{array}$ & 1.84 & $5.72 \mathrm{E}-33$ & 2.35 & $1.31 \mathrm{E}-09$ & 1.58 & $7.58 \mathrm{E}-16$ & 1.94 & $3.4 \mathrm{E}-05$ & 1.60 & $2.91 \mathrm{E}-11$ & 1.93 & $9.69 \mathrm{E}-04$ \\
\hline $\mathrm{A} 2 \mathrm{E}$ & in diantennary (A2) & 1.66 & $4.74 \mathrm{E}-26$ & 2.15 & $1.53 \mathrm{E}-08$ & 1.44 & $2.04 \mathrm{E}-11$ & 1.84 & $7.96 \mathrm{E}-05$ & 1.40 & $5.48 \mathrm{E}-07$ & 1.96 & $1.18 \mathrm{E}-03$ \\
\hline A2GE & per galactose in A2 & 1.76 & 7.36E-31 & 2.45 & $3.26 \mathrm{E}-10$ & 1.45 & $6.32 \mathrm{E}-12$ & 2.01 & $1.62 \mathrm{E}-05$ & 1.36 & $4.91 \mathrm{E}-06$ & 2.02 & $8.21 \mathrm{E}-04$ \\
\hline $\mathrm{A} 2 \mathrm{FE}$ & in fucosylated A2 & 1.63 & 4.82E-23 & 1.77 & $1.19 \mathrm{E}-05$ & 1.38 & 7.84E-09 & 1.36 & $3.48 \mathrm{E}-02$ & 1.45 & $1.51 \mathrm{E}-07$ & 1.64 & $1.15 \mathrm{E}-02$ \\
\hline A2FGE & $\begin{array}{l}\text { per galactose in fucosylated A2 } \\
\boldsymbol{\alpha 2 , 3 - s i a l y l a t i o n ~ ( L ) ~}\end{array}$ & 1.79 & $5.01 \mathrm{E}-30$ & 2.09 & $6.37 \mathrm{E}-08$ & 1.44 & $2.26 \mathrm{E}-10$ & 1.53 & $5.20 \mathrm{E}-03$ & 1.44 & $3.52 \mathrm{E}-07$ & 1.79 & $4.26 \mathrm{E}-03$ \\
\hline A3L & in triantennary (A3) & 0.45 & $1.32 \mathrm{E}-47$ & 0.33 & $2.42 \mathrm{E}-11$ & 0.58 & $1.36 \mathrm{E}-18$ & 0.50 & $1.42 \mathrm{E}-04$ & 0.60 & $6.38 \mathrm{E}-11$ & 0.54 & $1.08 \mathrm{E}-02$ \\
\hline A3FL & $\begin{array}{l}\text { in fucosylated A3 } \\
\text { IgG-related }\end{array}$ & 0.55 & 7.45E-29 & 0.42 & $4.76 \mathrm{E}-08$ & 0.69 & $3.35 \mathrm{E}-10$ & 0.60 & $2.85 \mathrm{E}-03$ & 0.69 & $1.02 \mathrm{E}-06$ & 0.53 & $5.68 \mathrm{E}-03$ \\
\hline TA2FS & fucosylated nonsialylated A2 & 0.69 & $5.90 \mathrm{E}-15$ & 0.59 & $1.69 \mathrm{E}-05$ & 0.74 & 8.07E-09 & 0.65 & $1.73 \mathrm{E}-03$ & 0.70 & $1.13 \mathrm{E}-08$ & 0.59 & $5.68 \mathrm{E}-03$ \\
\hline
\end{tabular}

Associations of $\mathrm{N}$-glycans with type 2 diabetes were assessed with logistic regression, and the Benjamini-Hochberg procedure was applied to control for multiple testing (cut-off at $5 \%$ false discovery rate). Glycan trait abbreviations are as follows: B, bisection; C, within complex; A2, diantennary; F, fucosylation; L, $\alpha 2,3$-linked sialylation; S, sialylation; G, galactose; E, $\alpha 2,6$-linked sialylation; A3, triantennary; T, within total. Negative associations with type 2 diabetes are shown in blue, positive associations in red. BMI, body mass index; HDL-c, HDL-cholesterol; OR, odds ratio; $p$, p-value.

Type 2 diabetes is a complex and multifactorial disease, characterized by metabolic disturbances often accompanied by obesity and low-grade systemic inflammation [34]. Considering the large disease burden of type 2 diabetes, a deeper insight into its pathophysiology 
is crucial. Studying protein $\mathrm{N}$-glycosylation as a common posttranslational modification with high complexity, diversity, and functional impact has high potential for advancing this knowledge. Associations of unspecific serum/plasma glycan markers, i.e. total levels of sialic acid and $\mathrm{N}$ acetylhexosamine, with inflammation and incident type 2 diabetes have previously been described and are partly explained by an absolute increase in acute phase proteins [23, 24, 35]. Our exploration of relative shifts of $\mathrm{N}$-glycan patterns may point at pathophysiological processes involving multiple proteins, as we discuss below.

\subsection{Sialylation}

We observed increased sialylation of fucosylated diantennary structures in type 2 diabetes patients, which has previously been reported for individuals at risk of developing diabetes as well as in acute (post-surgical) inflammation [11, 25, 36]. Sialic acids influence plasma protein clearance and are directly involved in activation and control of the immune system. Moreover, their functions depend on the linkage type [22,37]. Our finding of increased sialylation in diabetes and with increasing BMI was specifically due to $\alpha 2,6$-sialylation, while $\alpha 2,3$-sialylation decreased. Beta-galactoside alpha-2,6-sialyltransferase-1 (ST6Gal1), encoded by the ST6GAL1 gene, is the enzyme attaching $\alpha 2,6$-sialic acid to $N$-glycans [38]. Interestingly, polymorphisms of ST6GAL1 have been associated with type 2 diabetes in South East Asians [39], suggesting a potential causal relation between $\alpha 2,6$-sialylation and type 2 diabetes. ST6Gall enzyme activity was increased upon inflammation in both serum and liver in rats [40]. Moreover, an inflammation-limiting role of ST6Gal1 in plasma has been proposed in a study on aging [38]. It is tempting to speculate that increased ST6Gal1 enzyme activity may be a response to the low-grade chronic inflammation in type 2 diabetes.

The majority of the $\alpha 2,6$-sialylated diantennary fucosylated glycans (A2FGE) and the triantennary mono- $\alpha 2,6$-sialylated glycan H6N5E1, which were positively associated with type 2 diabetes in our study, are thought to be derived from soluble IgM and haptoglobin, respectively [33, 41, 42]. IgM and haptoglobin function as ligands for siglec-2 (CD22) [43], a sialic-acidbinding Ig-like lectin present on immune cells and pancreatic $\beta$-cells [44]. Increased $\alpha 2,6$-linked sialylation of IgM and haptoglobin might augment binding to $\mathrm{CD} 22$, and may thus have a role in inflammation and possibly also glucose homeostasis.

In contrast to $\alpha 2,6-$ linked sialylation, $\alpha 2,3-$ linked sialylation of larger glycans was lower in type 2 diabetes. The opposite was found in post-surgical, acute inflammation, where highly sialylated tri- and tetraantennary fucosylated glycans increased [11,36]. Moreover, both $\alpha 2,3$ - and $\alpha 2,6$-linked sialylation of larger glycans were higher in inflammatory bowel disease patients compared to healthy controls [45]. Large, sialylated, fucosylated glycans often contain terminal sialyl-Lewis X epitopes (consisting of an antennary fucose with an $\alpha 2,3$-linked sialic acid), especially on acute-phase proteins $[33,35,46]$. Increased abundance of sialyl-Lewis $X$ epitopes on plasma glycoproteins during inflammation has been postulated to exert anti-inflammatory effects through competitive binding to endothelial E-selectin and blocking of immune-cell adhesion and extravasation into tissues [47]. Thus, reduced $\alpha 2,3$-linked sialylation in type 2 
diabetes might be a sign of either disrupted anti-inflammatory mechanisms or other processes specific to type 2 diabetes that are not related to inflammation. Since data on sialylation in disease states is scarce, it remains unclear whether reduced $\alpha 2,3$-linked sialylation is only seen in diabetes or also in other diseases.
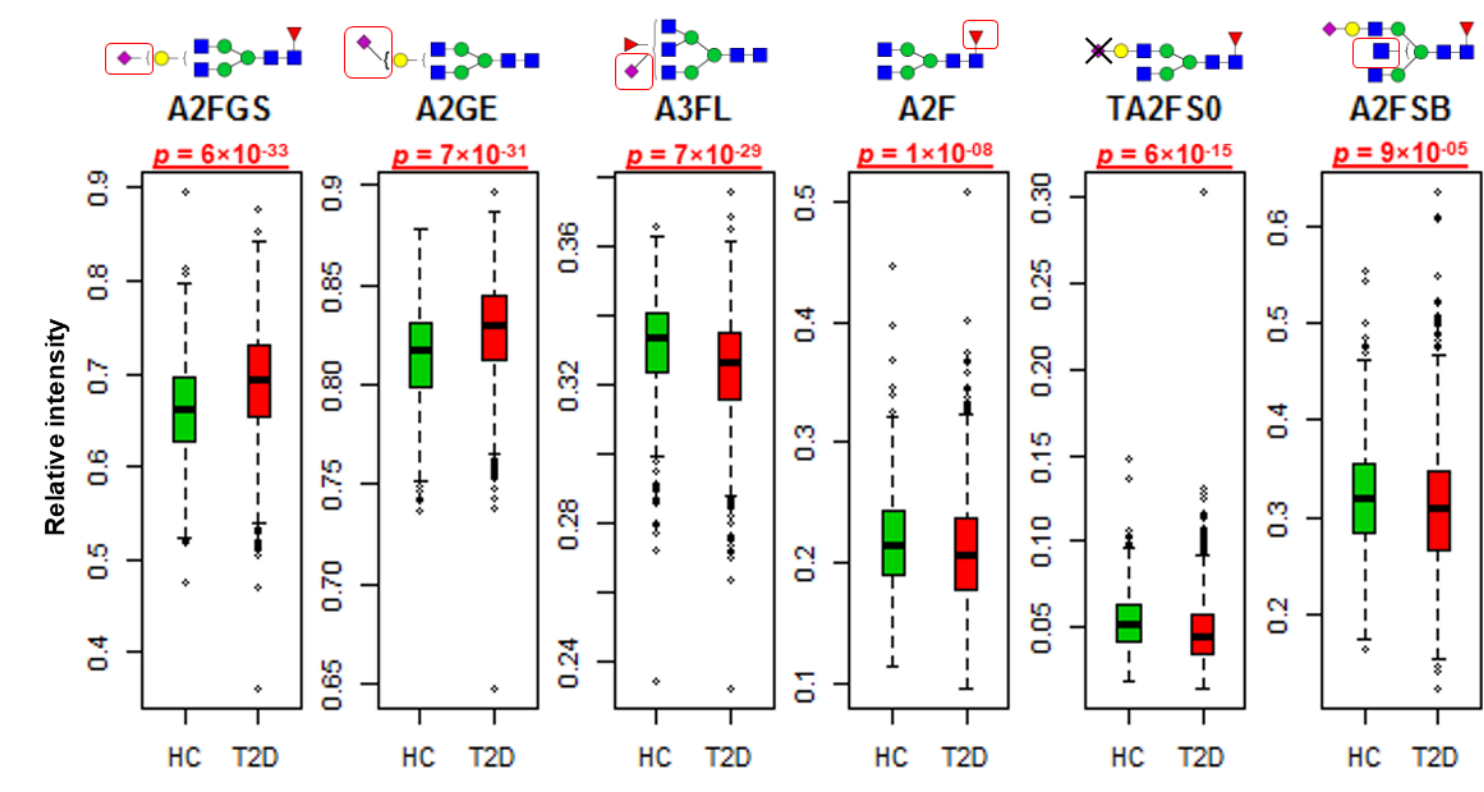

Figure 3: Selected derived glycan traits in healthy controls (HC, green) and individuals with type 2 diabetes (T2D, red) from the discovery cohort. The 25th, 50th and 75th percentiles and whiskers at $1 \mathrm{st}$ quartile minus $1.5 *$ interquartile range $(\mathrm{Q} 1-1.5 * \mathrm{IQR})$ and $\mathrm{Q} 3+1.5 * \mathrm{IQR}$ of the relative intensities are shown. P-values are shown for significant, replicated associations after adjustment for age, sex, and their interaction (model 1). See Table 2 for the entire list of replicated associations and Supplementary Table S2 for details on the derived glycan traits. A2, diantennary; F, fucosylation; G, galactosylation; S, sialylation; E, $\alpha 2,6$-linked sialylation; A3, triantennary; L, $\alpha 2,3$-linked sialylation; T, in total spectrum; B, bisection.

\subsection{Fucosylation}

We observed a decrease in fucosylation of diantennary glycans (A2F) in type 2 diabetes, which has also been linked to inflammation [36], increased C-reactive protein levels, and smoking [15]. This decrease was driven by decreases of the fucosylated species H4N4F1(E1), H5N4F1(E1), $\mathrm{H} 5 \mathrm{~N} 5 \mathrm{~F} 1, \mathrm{H} 3 \mathrm{~N} 4 \mathrm{~F} 1$, and H4N5F1. In healthy individuals, these glycans are mostly derived from IgG, and partly from other Igs [33, 48]. Thus, the decreased fucosylation of diantennary glycans might reflect a relative decrease of IgG glycans. Accordingly, decreased absolute IgG levels have been reported in type 2 diabetes [49]. Moreover, we recently found decreased fucosylation of nonsialylated, non-bisected IgG glycans in type 2 diabetes [19], which enhances the antibodydependent cytotoxicity of IgG [50]. In contrast, Itoh et al. found an increased relative amount of the core-fucosylated bisected diantennary glycan (H5N5F1) in sera of individuals with type 2 diabetes [51]. However, a low-resolution analytical technique was used, bearing the risk of an 
overlap of different structures, and results were not adjusted for age, sex and risk factors for diabetes.

Our MS-based glycomics technique does not reveal whether a fucose is attached to an antennary $\mathrm{N}$-acetylglucosamine or to the core. However, chromatographic analyses indicate that diantennary glycans mostly carry core-fucoses, while tri- and tetraantennary structures are more likely to carry antennary fucoses $[12,36]$. Fucosylation co-occurring with an $\alpha 2,3$-linked sialic acid could indicate an antennary fucose within a sialyl-Lewis $X$ epitope, as discussed in the sialylation paragraph. As an approximation of antennary fucosylation, we used glycans bearing two fucoses, which are represented by traits $\mathrm{A} 3 \mathrm{Fa}$ and $\mathrm{A} 4 \mathrm{Fa}$ and imply the presence of at least one antennary fucose. These were positively associated with age, BMI and smoking, but not with diabetes. Accordingly, in a previous report, no differences were found in the proportion of antennary fucosylated triantennary glycans between type 2 diabetes and healthy controls. In contrast, individuals with MODY3 showed decreased antennary fucosylation of triantennary glycans compared to both healthy and type 2 diabetes individuals [5]. MODY3 is caused by mutations in the HNF1A gene, which is thought to regulate fucosyltransferase activity and to modulate antennary fucosylation [12]. Since we found no change in antennary fucosylation in type 2 diabetes, the decreased fucosylation is more likely caused by decreased diantennary corefucosylated (Ig-derived) glycans.

\subsection{Bisection}

The addition of an $\mathrm{N}$-acetylglucosamine in $\beta 1,4$-linkage to the first mannose of the $\mathrm{N}$ glycan core by $N$-acetylglucosamine-transferase- 3 is called bisection. This process is in competition with other glycosyltransferases, including fucosyltransferase- 8 for core-fucosylation and $\mathrm{N}$-acetylglucosamine-transferase-5 for branching [52]. Bisection of fucosylated sialylated diantennary glycans (A2FSB) was reduced in type 2 diabetes in our cohort, while IgG-related bisection in the non-sialylated variant (A2FS0B) tended to increase, in agreement with our previous findings in isolated $\mathrm{IgG}$ [19]. Also, in an independent large cohort of mostly healthy individuals, the A2FSB trait showed a positive trend $(p=0.017)$ with increasing glucose-to-insulin ratio [15], indicative of a higher insulin sensitivity and supporting our finding in diabetes. Interestingly, A2FSB showed a positive association with rheumatoid arthritis, which is characterized by chronic inflammation [53]. In IgG, bisection enhances antibody-dependent cytotoxicity [50]. The biological effects of bisection in IgA and IgM glycans are largely unknown. A2FSB $N$-glycans are mostly derived from IgA, IgM, and the fragment antigen-binding portion of $\mathrm{IgG}$, while non-bisected A2FS are mostly attributable to a mixture of glycoproteins released by the liver (i.e. acute phase proteins) [33]. Therefore, the decreased A2FSB possibly also reflects a decrease in $N$-glycans derived from Igs.

\subsection{Galactosylation}

Various galactosylation traits in diantennary glycans (A2G) were positively associated with type 2 diabetes in the first 2 models, but lost statistical significance in the replication cohort after adjustment for risk factors for type 2 diabetes. The latter might be due either to a power issue in 
the smaller replication cohort or to a causal relationship of the risk factors with A2G. Very recently, increased galactosylation was associated with an increased risk of type 2 diabetes (age- and sexadjusted), in line with our findings in model 1 and 2 [25]. Beta-1,4-galactosyltransferases are responsible for galactosylation, and their activity in plasma has been associated with aging and diabetes [38, 54]. In contrast, IgG-related galactosylation (A2FS0G) tended to decrease in diabetes, which is in line with our study on $\operatorname{IgG}$ [19]. While a decrease in IgG galactosylation is a well-described phenomenon in different types of inflammation and aging [55], it remains unclear which mechanisms contribute to an increase of galactosylation in non-IgG plasma $N$-glycans.

\subsection{Glycan complexity}

We observed a positive association of triantennary (CA3) and a negative association of diantennary glycans (CA2) with type 2 diabetes in all models, although only replicated for model 1. Similarly, increased branching was associated with type 2 diabetes risk after adjustment for age and sex [25]. However, the decreased association strength after correction for BMI and other risk factors in our study suggests that higher glycan complexity is mediated through these risk factors.

Lastly, the decreased ratio of high-mannose to hybrid glycans (MHy) in type 2 diabetes in models 1 and 2 could be due to decreased apolipoprotein B-100 levels in cases, since high-mannose plasma glycans are, for a large part, derived from this apolipoprotein [33]. This is reflected by the lower non-HDL-c in cases than controls, explained by the use of lipid-lowering treatment. Accordingly, after adjustment for lipids in model 3 this association lost significance in both cohorts.

\subsection{Strengths and limitations}

A major advantage of this study is that we were able to reliably identify and quantify 70 different plasma $\mathrm{N}$-glycan structures in a large type 2 diabetes case-control study, while others have focused on fewer structures with low-resolution techniques in smaller sample sizes. Our approach with sialic-acid derivatization provided unique insights into sialic-acid linkage-specific changes. The size of our discovery cohort ensured establishing robust associations between glycans and type 2 diabetes, even after adjustment for multiple risk factors for type 2 diabetes.

Nonetheless, several limitations apply to our findings. First, the glycan species analyzed often represent isomer mixtures, except for sialic-acid linkage isomers. Second, our data are normalized to the total area of the 70 detected structures and, for this reason, are dependent on the plasma levels of the respective glycoproteins. Future glycomic investigations on a protein-specific level, as previously studied in the DiaGene study for IgG [19], combined with data on the plasma levels of these proteins will give a deeper insight into the mechanisms underlying our observations. Currently, however, this is still beyond technical capabilities for large-scale studies. Third, a separate similar cohort was not available to replicate our findings. Instead, we created a randomly selected, age- and sex-matched subcohort for replication, which was smaller and therefore some true associations may not have become significant in this cohort. Fourth, our data is cross-sectional and therefore does not allow conclusions on the causality of the associations, although recent findings in individuals at risk of type 2 diabetes [25] are supportive of our results and do point in 
the direction of a causal relationship. Our results are a starting point for future research in independent prospective cohorts. Last, we were not able to adjust for possible effects of diabetes treatment on $\mathrm{N}$-glycan profiles due to the absolute association of the endpoint (diabetes) with the treatment. Collaborations are ongoing to assess treatment effects in the future.

\section{CONCLUSIONS}

In this cross-sectional study, we found robust associations between type 2 diabetes and the plasma $N$-glycome, especially regarding sialic-acid linkages. In part, glycans in type 2 diabetes appear to reflect a pro-inflammatory state. However, not all associations seem to be explained by inflammation, such as the observed decrease in $\alpha 2,3$-linked sialylation. Further studies should focus on protein-specific glycosylation changes. Moreover, prospective and genetic studies including Mendelian randomization and expression levels of glycosyltransferases and glycosidases should shed light on the causality and mechanisms involved. Eventually, knowledge on altered $\mathrm{N}$-glycosylation, an essential but understudied physiological process, has the potential to improve insight in the pathophysiology of type 2 diabetes and could contribute to decreasing the burden of this major disease.

\section{ACKNOWLEDGEMENTS}

We are grateful to Carolien AM Koeleman for her technical support during the glycomics measurements.

\section{DATA STATEMENT}

Mass spectrometric data of the standard samples is available on Mendeley Data, under https://data.mendeley.com/datasets/zt3xb42ngz/2; DOI: 10.17632/zt3xb42ngz.2. Other data are available from the corresponding author upon reasonable request.

\section{FUNDING}

This study was funded by the individual Erasmus MC Fellowship Grant of Mandy van Hoek (glycan analysis) and by the European Union FP7 grant "HighGlycan" under grant agreement HEALTH-F5-2011-278535 (K.R.R., A.L.H.E. and M.W.). The funding sources were not involved in in study design; in the collection, analysis and interpretation of data, the writing of the report, or the decision to submit the article for publication.

The data that support the findings of this study are available from the corresponding author upon reasonable request. 


\section{DECLARATION OF INTEREST}

K.R.R. and M.W. are inventors on a patent application on sialic acid derivatization by ethyl esterification. V.D., R.L, M.v.H, M.T.M, E.J.G.S, A.G.L., and A.L.H.E. declare no conflicts of interest.

\section{CONTRIBUTION STATEMENT}

E.J.G.S. and M.v.H. conceived the clinical study; E.J.G.S, M.v.H., A.G.L., M.T.M., and R.F.H.L. conducted the clinical study and maintained the clinical files and database. M.W. conceived the glycomic experiments; A.L.H.E. conducted glycomic analysis; A.L.H.E. and V.D. processed glycomic raw data; R.F.H.L. conducted the experiments on non-glycomic analyses. V.D., R.F.H.L., K.R.R., E.J.G.S., M.W. and M.v.H. developed the strategy for statistical analysis. K.R.R. developed the R-scripts for data analysis. V.D. and R.F.H.L. analysed data and wrote the manuscript. M.W., K.R.R., E.J.G.S. and M.v.H. edited the manuscript. All authors reviewed the manuscript and have given approval to the final version of the manuscript.

\section{REFERENCES}

[1] WHO, Global report on diabetes, World Health Organization, 2016.

[2] P. Gaede, P. Vedel, N. Larsen, G.V. Jensen, H.H. Parving, O. Pedersen, Multifactorial intervention and cardiovascular disease in patients with type 2 diabetes, The New England journal of medicine, 348 (2003) 383-393.

[3] C.J. Nolan, P. Damm, M. Prentki, Type 2 diabetes across generations: from pathophysiology to prevention and management, The Lancet, 378 (2011) 169-181.

[4] G. Lauc, M. Pezer, I. Rudan, H. Campbell, Mechanisms of disease: The human N-glycome, Biochim. Biophys. Acta, Gen. Subj. , 1860 (2016) 1574-1582.

[5] G. Thanabalasingham, J.E. Huffman, J.J. Kattla, M. Novokmet, I. Rudan, A.L. Gloyn, C. Hayward, B. Adamczyk, R.M. Reynolds, A. Muzinic, N. Hassanali, M. Pucic, A.J. Bennett, A. Essafi, O. Polasek, S.A. Mughal, I. Redzic, D. Primorac, L. Zgaga, I. Kolcic, T. Hansen, D. Gasperikova, E. Tjora, M.W.J. Strachan, T. Nielsen, J. Stanik, I. Klimes, O.B. Pedersen, P.R. Njølstad, S.H. Wild, U. Gyllensten, O. Gornik, J.F. Wilson, N.D. Hastie, H. Campbell, M.I. McCarthy, P.M. Rudd, K.R. Owen, G. Lauc, A.F. Wright, Mutations in HNF1A Result in Marked Alterations of Plasma Glycan Profile, Diabetes, 62 (2013) 1329.

[6] A.G. McDonald, J.M. Hayes, G.P. Davey, Metabolic flux control in glycosylation, Current opinion in structural biology, 40 (2016) 97-103.

[7] M.I. McCarthy, Painting a new picture of personalised medicine for diabetes, Diabetologia, 60 (2017) 793-799.

[8] A. Varki, Biological roles of glycans, Glycobiology, 27 (2017) 3-49.

[9] S. Ahmad, M.S. Khan, F. Akhter, M.S. Khan, A. Khan, J.M. Ashraf, R.P. Pandey, U. Shahab, Glycoxidation of Biological Macromolecules: A Critical Approach to Halt the Menace of Glycation, Glycobiology, 24 (2014) 979-990. 
[10] R. Hennig, S. Cajic, M. Borowiak, M. Hoffmann, R. Kottler, U. Reichl, E. Rapp, Towards personalized diagnostics via longitudinal study of the human plasma N-glycome, Biochimica et biophysica acta, 1860 (2016) 1728-1738.

[11] M. Novokmet, E. Lukić, F. Vučković, Ž. -Durić, T. Keser, K. Rajšl, D. Remondini, G. Castellani, H. Gašparović, O. Gornik, G. Lauc, Changes in IgG and total plasma protein glycomes in acute systemic inflammation, Scientific Reports, 4 (2014) 4347.

[12] A. Knežević, O. Gornik, O. Polašek, M. Pučić, I. Redžić, M. Novokmet, P.M. Rudd, A.F. Wright, H. Campbell, I. Rudan, G. Lauc, Effects of aging, body mass index, plasma lipid profiles, and smoking on human plasma N-glycans, Glycobiology, 20 (2010) 959-969.

[13] J. Krištić, F. Vučković, C. Menni, L. Klarić, T. Keser, I. Beceheli, M. Pučić-Baković, M. Novokmet, M. Mangino, K. Thaqi, P. Rudan, N. Novokmet, J. Šarac, S. Missoni, I. Kolčić, O. Polašek, I. Rudan, H. Campbell, C. Hayward, Y. Aulchenko, A. Valdes, J.F. Wilson, O. Gornik, D. Primorac, V. Zoldoš, T. Spector, G. Lauc, Glycans Are a Novel Biomarker of Chronological and Biological Ages, The Journals of Gerontology: Series A, 69 (2014) 779-789.

[14] L.R. Ruhaak, H.W. Uh, M. Beekman, C.H. Hokke, R.G. Westendorp, J. Houwing-Duistermaat, M. Wuhrer, A.M. Deelder, P.E. Slagboom, Plasma protein N-glycan profiles are associated with calendar age, familial longevity and health, Journal of proteome research, 10 (2011) 1667-1674.

[15] K.R. Reiding, L.R. Ruhaak, H.-W. Uh, S. el Bouhaddani, E.B. van den Akker, R. Plomp, L.A. McDonnell, J.J. Houwing-Duistermaat, P.E. Slagboom, M. Beekman, M. Wuhrer, Human Plasma Nglycosylation as Analyzed by Matrix-Assisted Laser Desorption/Ionization-Fourier Transform Ion Cyclotron Resonance-MS Associates with Markers of Inflammation and Metabolic Health, Mol. Cell. Proteomics 16 (2017) 228-242.

[16] G. Lauc, A. Essafi, J.E. Huffman, C. Hayward, A. Knežević, J.J. Kattla, O. Polašek, O. Gornik, V. Vitart, J.L. Abrahams, M. Pučić, M. Novokmet, I. Redžić, S. Campbell, S.H. Wild, F. Borovečki, W. Wang, I. Kolčić, L. Zgaga, U. Gyllensten, J.F. Wilson, A.F. Wright, N.D. Hastie, H. Campbell, P.M. Rudd, I. Rudan, Genomics Meets Glycomics - The First GWAS Study of Human N-Glycome Identifies HNF1 $\alpha$ as a Master Regulator of Plasma Protein Fucosylation, PLOS Genetics, 6 (2010) e1001256.

[17] T.J. McDonald, S. Ellard, Maturity onset diabetes of the young: identification and diagnosis, Ann. Clin. Biochem., 50 (2013) 403-415.

[18] B.F. Voight, L.J. Scott, V. Steinthorsdottir, A.P. Morris, C. Dina, R.P. Welch, E. Zeggini, C. Huth, Y.S. Aulchenko, G. Thorleifsson, L.J. McCulloch, T. Ferreira, H. Grallert, N. Amin, G. Wu, C.J. Willer, S. Raychaudhuri, S.A. McCarroll, C. Langenberg, O.M. Hofmann, J. Dupuis, L. Qi, A.V. Segre, M. van Hoek, P. Navarro, K. Ardlie, B. Balkau, R. Benediktsson, A.J. Bennett, R. Blagieva, E. Boerwinkle, L.L. Bonnycastle, K.B. Bostrom, B. Bravenboer, S. Bumpstead, N.P. Burtt, G. Charpentier, P.S. Chines, M. Cornelis, D.J. Couper, G. Crawford, A.S.F. Doney, K.S. Elliott, A.L. Elliott, M.R. Erdos, C.S. Fox, C.S. Franklin, M. Ganser, C. Gieger, N. Grarup, T. Green, S. Griffin, C.J. Groves, C. Guiducci, S. Hadjadj, N. Hassanali, C. Herder, B. Isomaa, A.U. Jackson, P.R.V. Johnson, T. Jorgensen, W.H.L. Kao, N. Klopp, A. Kong, P. Kraft, J. Kuusisto, T. Lauritzen, M. Li, A. Lieverse, C.M. Lindgren, V. Lyssenko, M. Marre, T. Meitinger, K. Midthjell, M.A. Morken, N. Narisu, P. Nilsson, K.R. Owen, F. Payne, J.R.B. Perry, A.-K. Petersen, C. Platou, C. Proenca, I. Prokopenko, W. Rathmann, N.W. Rayner, N.R. Robertson, G. Rocheleau, M. Roden, M.J. Sampson, R. Saxena, B.M. Shields, P. Shrader, G. Sigurdsson, T. Sparso, K. Strassburger, H.M. Stringham, Q. Sun, A.J. Swift, B. Thorand, J. Tichet, T. Tuomi, R.M. van Dam, T.W. van Haeften, T. van Herpt, J.V. van Vliet-Ostaptchouk, G.B. Walters, M.N. Weedon, C. Wijmenga, J. Witteman, R.N. Bergman, S. Cauchi, F.S. Collins, A.L. Gloyn, U. Gyllensten, T. Hansen, W.A. Hide, G.A. 
Hitman, A. Hofman, D.J. Hunter, K. Hveem, M. Laakso, K.L. Mohlke, A.D. Morris, C.N.A. Palmer, P.P. Pramstaller, I. Rudan, E. Sijbrands, L.D. Stein, J. Tuomilehto, A. Uitterlinden, M. Walker, N.J. Wareham, R.M. Watanabe, G.R. Abecasis, B.O. Boehm, H. Campbell, M.J. Daly, A.T. Hattersley, F.B. Hu, J.B. Meigs, J.S. Pankow, O. Pedersen, H.E. Wichmann, I. Barroso, J.C. Florez, T.M. Frayling, L. Groop, R. Sladek, U. Thorsteinsdottir, J.F. Wilson, T. Illig, P. Froguel, C.M. van Duijn, K. Stefansson, D. Altshuler, M. Boehnke, M.I. McCarthy, Twelve type 2 diabetes susceptibility loci identified through large-scale association analysis, Nat. Genet., 42 (2010) 579-589.

[19] R.F.H. Lemmers, M. Vilaj, D. Urda, F. Agakov, M. Šimurina, L. Klaric, I. Rudan, H. Campbell, C. Hayward, J.F. Wilson, A.G. Lieverse, O. Gornik, E.J.G. Sijbrands, G. Lauc, M. van Hoek, IgG glycan patterns are associated with type 2 diabetes in independent European populations, Biochim. Biophys. Acta, Gen. Subj. , 1861 (2017) 2240-2249.

[20] K. Tanigaki, A. Sacharidou, J. Peng, K.L. Chambliss, I.S. Yuhanna, D. Ghosh, M. Ahmed, A.J. Szalai, W. Vongpatanasin, R.F. Mattrey, Q. Chen, P. Azadi, I. Lingvay, M. Botto, W.L. Holland, J.J. Kohler, S.R. Sirsi, K. Hoyt, P.W. Shaul, C. Mineo, Hyposialylated IgG activates endothelial IgG receptor FcgammaRIIB to promote obesity-induced insulin resistance, The Journal of clinical investigation, $10.1172 /$ jci89333 (2017).

[21] R. Testa, V. Vanhooren, A.R. Bonfigli, M. Boemi, F. Olivieri, A. Ceriello, S. Genovese, L. Spazzafumo, V. Borelli, M.G. Bacalini, S. Salvioli, P. Garagnani, S. Dewaele, C. Libert, C. Franceschi, NGlycomic Changes in Serum Proteins in Type 2 Diabetes Mellitus Correlate with Complications and with Metabolic Syndrome Parameters, PLOS ONE, 10 (2015) e0119983.

[22] A. Varki, P. Gagneux, Multifarious roles of sialic acids in immunity, Ann. N. Y. Acad. Sci., 1253 (2012) 16-36.

[23] M.I. Schmidt, B.B. Duncan, A.R. Sharrett, G. Lindberg, P.J. Savage, S. Offenbacher, M.I. Azambuja, R.P. Tracy, G. Heiss, Markers of inflammation and prediction of diabetes mellitus in adults (Atherosclerosis Risk in Communities study): a cohort study, The Lancet, 353 (1999) 1649-1652.

[24] A.O. Akinkuolie, A.D. Pradhan, J.E. Buring, P.M. Ridker, S. Mora, Novel Protein Glycan Side-Chain Biomarker and Risk of Incident Type 2 Diabetes Mellitus, Arterioscler., Thromb., Vasc. Biol. , 35 (2015) 1544.

[25] T. Keser, I. Gornik, F. Vuckovic, N. Selak, T. Pavic, E. Lukic, I. Gudelj, H. Gasparovic, B. Biocina, T. Tilin, A. Wennerstrom, S. Mannisto, V. Salomaa, A. Havulinna, W. Wang, J.F. Wilson, N. Charutvedi, M. Perola, H. Campbell, G. Lauc, O. Gornik, Increased plasma N-glycome complexity is associated with higher risk of type 2 diabetes, Diabetologia, 10.1007/s00125-017-4426-9 (2017).

[26] K.R. Reiding, D. Blank, D.M. Kuijper, A.M. Deelder, M. Wuhrer, High-throughput profiling of protein $\mathrm{N}$-glycosylation by MALDI-TOF-MS employing linkage-specific sialic acid esterification, Analytical chemistry, 86 (2014) 5784-5793.

[27] T.T.W. van Herpt, R.F.H. Lemmers, M. van Hoek, J.G. Langendonk, R.J. Erdtsieck, B. Bravenboer, A. Lucas, M.T. Mulder, H.R. Haak, A.G. Lieverse, E.J.G. Sijbrands, Introduction of the DiaGene study: clinical characteristics, pathophysiology and determinants of vascular complications of type 2 diabetes, Diabetol. Metab. Syndr., 9 (2017) 47.

[28] M.R. Bladergroen, K.R. Reiding, A.L. Hipgrave Ederveen, G.C. Vreeker, F. Clerc, S. Holst, A. Bondt, M. Wuhrer, Y.E. van der Burgt, Automation of High-Throughput Mass Spectrometry-Based Plasma NGlycome Analysis with Linkage-Specific Sialic Acid Esterification, Journal of proteome research, 14 (2015) 4080-4086. 
[29] B.C. Jansen, K.R. Reiding, A. Bondt, A.L. Hipgrave Ederveen, M. Palmblad, D. Falck, M. Wuhrer, MassyTools: A High-Throughput Targeted Data Processing Tool for Relative Quantitation and Quality Control Developed for Glycomic and Glycoproteomic MALDI-MS, Journal of proteome research, 14 (2015) 5088-5098.

[30] F. Clerc, K.R. Reiding, B.C. Jansen, G.S.M. Kammeijer, A. Bondt, M. Wuhrer, Human plasma protein N-glycosylation, Glycoconjugate Journal, 33 (2016) 309-343.

[31] F. Faul, E. Erdfelder, A. Buchner, A.G. Lang, Statistical power analyses using G*Power 3.1: tests for correlation and regression analyses, Behavior research methods, 41 (2009) 1149-1160.

[32] Y. Benjamini, Y. Hochberg, Controlling the False Discovery Rate: A Practical and Powerful Approach to Multiple Testing, Journal of the Royal Statistical Society. Series B (Methodological), 57 (1995) 289300.

[33] F. Clerc, K.R. Reiding, B.C. Jansen, G.S.M. Kammeijer, A. Bondt, M. Wuhrer, Human plasma protein N-glycosylation, Glycoconjugate J. , 33 (2016) 309-343.

[34] G.S. Hotamisligil, Inflammation, metaflammation and immunometabolic disorders, Nature, 542 (2017) $177-185$.

[35] C. McCarthy, R. Saldova, M.R. Wormald, P.M. Rudd, N.G. McElvaney, E.P. Reeves, The Role and Importance of Glycosylation of Acute Phase Proteins with Focus on Alpha-1 Antitrypsin in Acute and Chronic Inflammatory Conditions, Journal of proteome research, 13 (2014) 3131-3143.

[36] I. Gudelj, M. Baciarello, I. Ugrina, M. De Gregori, V. Napolioni, P.M. Ingelmo, D. Bugada, S. De Gregori, L. Đerek, M. Pučić-Baković, M. Novokmet, O. Gornik, G. Saccani Jotti, T. Meschi, G. Lauc, M. Allegri, Changes in total plasma and serum N-glycome composition and patient-controlled analgesia after major abdominal surgery, Scientific Reports, 6 (2016) 31234.

[37] T.R. McCurdy, V. Bhakta, L.J. Eltringham-Smith, S. Gataiance, A.E. Fox-Robichaud, W.P. Sheffield, In Vivo Clearance of Alpha-1 Acid Glycoprotein Is Influenced by the Extent of Its N-Linked Glycosylation and by Its Interaction with the Vessel Wall, J. Biomed. Biotechnol., 2012 (2012) 11.

[38] M. Catera, V. Borelli, N. Malagolini, M. Chiricolo, G. Venturi, C.A. Reis, H. Osorio, P.M. Abruzzo, M. Capri, D. Monti, R. Ostan, C. Franceschi, F. Dall'Olio, Identification of novel plasma glycosylationassociated markers of aging, Oncotarget, 7 (2016) 7455-7468.

[39] J.S. Kooner, D. Saleheen, X. Sim, J. Sehmi, W. Zhang, P. Frossard, L.F. Been, K.-S. Chia, A.S. Dimas, N. Hassanali, T. Jafar, J.B.M. Jowett, X. Li, V. Radha, S.D. Rees, F. Takeuchi, R. Young, T. Aung, A. Basit, M. Chidambaram, D. Das, E. Grundberg, A.K. Hedman, Z.I. Hydrie, M. Islam, C.-C. Khor, S. Kowlessur, M.M. Kristensen, S. Liju, W.-Y. Lim, D.R. Matthews, J. Liu, A.P. Morris, A.C. Nica, J.M. Pinidiyapathirage, I. Prokopenko, A. Rasheed, M. Samuel, N. Shah, A.S. Shera, K.S. Small, C. Suo, A.R. Wickremasinghe, T.Y. Wong, M. Yang, F. Zhang, G.R. Abecasis, A.H. Barnett, M. Caulfield, P. Deloukas, T.M. Frayling, P. Froguel, N. Kato, P. Katulanda, M.A. Kelly, J. Liang, V. Mohan, D.K. Sanghera, J. Scott, M. Seielstad, P.Z. Zimmet, P. Elliott, Y.Y. Teo, M.I. McCarthy, J. Danesh, E.S. Tai, J.C. Chambers, Genome-wide association study in individuals of South Asian ancestry identifies six new type 2 diabetes susceptibility loci, Nat. Genet., 43 (2011) 984-989.

[40] H.A. Kaplan, B.M. Woloski, M. Hellman, J.C. Jamieson, Studies on the effect of inflammation on rat liver and serum sialyltransferase. Evidence that inflammation causes release of Gal beta 1 leads to 4GlcNAc alpha 2 leads to 6 sialyltransferase from liver, J. Biol. Chem. , 258 (1983) 11505-11509.

[41] J.N. Arnold, M.R. Wormald, D.M. Suter, C.M. Radcliffe, D.J. Harvey, R.A. Dwek, P.M. Rudd, R.B. Sim, Human serum IgM glycosylation: identification of glycoforms that can bind to mannan-binding lectin, J. Biol. Chem., 280 (2005) 29080-29087. 
[42] S. Zhang, K. Jiang, C. Sun, H. Lu, Y. Liu, Quantitative analysis of site-specific N-glycans on sera haptoglobin beta chain in liver diseases, Acta biochimica et biophysica Sinica, 45 (2013) 1021-1029.

[43] K. Hanasaki, L.D. Powell, A. Varki, Binding of Human Plasma Sialoglycoproteins by the B Cellspecific Lectin CD22: SELECTIVE RECOGNITION OF IMMUNOGLOBULIN M AND HAPTOGLOBIN, J. Biol. Chem. , 270 (1995) 7543-7550.

[44] G. Dharmadhikari, K. Stolz, M. Hauke, N.G. Morgan, A. Varki, E. de Koning, S. Kelm, K. Maedler, Siglec-7 restores $\beta$-cell function and survival and reduces inflammation in pancreatic islets from patients with diabetes, Scientific Reports, 7 (2017) 45319.

[45] F. Clerc, M. Novokmet, V. Dotz, K.R. Reiding, N. de Haan, G.S.M. Kammeijer, H. Dalebout, M.R. Bladergroen, F. Vukovic, E. Rapp, I.-B. consortium, S.R. Targan, G. Barron, N. Manetti, A. Latiano, D.P.B. McGovern, V. Annese, G. Lauc, M. Wuhrer, Plasma N-Glycan Signatures Associate With Features of Inflammatory Bowel Diseases, Gastroenterology, 10.1053/j.gastro.2018.05.030 (2018).

[46] E.C. Brinkman-van der Linden, P.F. de Haan, E.C. Havenaar, W. van Dijk, Inflammation-induced expression of sialyl LewisX is not restricted to alpha1-acid glycoprotein but also occurs to a lesser extent on alpha1-antichymotrypsin and haptoglobin, Glycoconjugate J. , 15 (1998) 177-182.

[47] H.G. Jorgensen, M.A. Elliott, R. Priest, K.D. Smith, Modulation of sialyl Lewis X dependent binding to E-selectin by glycoforms of alpha-1-acid glycoprotein expressed in rheumatoid arthritis, Biomedical chromatography : BMC, 12 (1998) 343-349.

[48] M. Colucci, H. Stöckmann, A. Butera, A. Masotti, A. Baldassarre, E. Giorda, S. Petrini, P.M. Rudd, R. Sitia, F. Emma, M. Vivarelli, Sialylation of N-Linked Glycans Influences the Immunomodulatory Effects of IgM on T Cells, J. Immunol., 194 (2014) 151.

[49] X. Guo, G. Meng, F. Liu, Q. Zhang, L. Liu, H. Wu, H. Du, H. Shi, Y. Xia, X. Liu, C. Li, X. Bao, Q. Su, Y. Gu, L. Fang, F. Yu, H. Yang, B. Yu, S. Sun, X. Wang, M. Zhou, Q. Jia, X. Chen, G. Huang, K. Song, K. Niu, Serum levels of immunoglobulins in an adult population and their relationship with type 2 diabetes, Diabetes Res. Clin. Pract., 115 (2016) 76-82.

[50] T. Shinkawa, K. Nakamura, N. Yamane, E. Shoji-Hosaka, Y. Kanda, M. Sakurada, K. Uchida, H. Anazawa, M. Satoh, M. Yamasaki, N. Hanai, K. Shitara, The absence of fucose but not the presence of galactose or bisecting $\mathrm{N}$-acetylglucosamine of human IgG1 complex-type oligosaccharides shows the critical role of enhancing antibody-dependent cellular cytotoxicity, J. Biol. Chem. , 278 (2003) 3466-3473. [51] N. Itoh, S. Sakaue, H. Nakagawa, M. Kurogochi, H. Ohira, K. Deguchi, S.-I. Nishimura, M. Nishimura, Analysis of N-glycan in serum glycoproteins from $\mathrm{db} / \mathrm{db}$ mice and humans with type 2 diabetes, Am. J. Physiol. Endocrinol. Metabolism, 293 (2007) E1069.

[52] A. Kurimoto, S. Kitazume, Y. Kizuka, K. Nakajima, R. Oka, R. Fujinawa, H. Korekane, Y. Yamaguchi, Y. Wada, N. Taniguchi, The Absence of Core Fucose Up-regulates GnT-III and Wnt Target Genes: A POSSIBLE MECHANISM FOR AN ADAPTIVE RESPONSE IN TERMS OF GLYCAN FUNCTION, J. Biol. Chem. , 289 (2014) 11704-11714.

[53] K.R. Reiding, G.C.M. Vreeker, A. Bondt, M.R. Bladergroen, J.M.W. Hazes, Y.E.M. van der Burgt, M. Wuhrer, R. Dolhain, Serum Protein N-Glycosylation Changes with Rheumatoid Arthritis Disease Activity during and after Pregnancy, Frontiers in medicine, 4 (2017) 241.

[54] L.P. Lee, A. Prasad, K.J. Bolton, J.B. McKendry, I. Hynie, Serum UDP-galactose: glycoprotein galactosyltransferase in diabetics with microangiopathy, Clin. Biochem., 10 (1977) 111-117.

[55] F. Dall'Olio, V. Vanhooren, C.C. Chen, P.E. Slagboom, M. Wuhrer, C. Franceschi, N-glycomic biomarkers of biological aging and longevity: A link with inflammaging, Ageing Res. Rev., 12 (2013) 685698. 